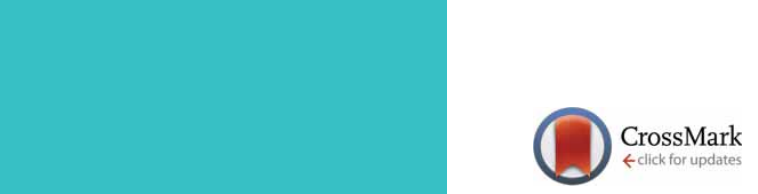

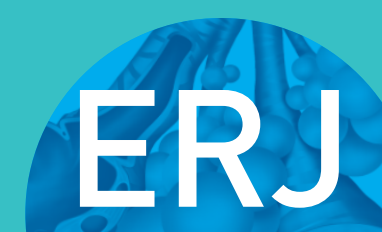

open research
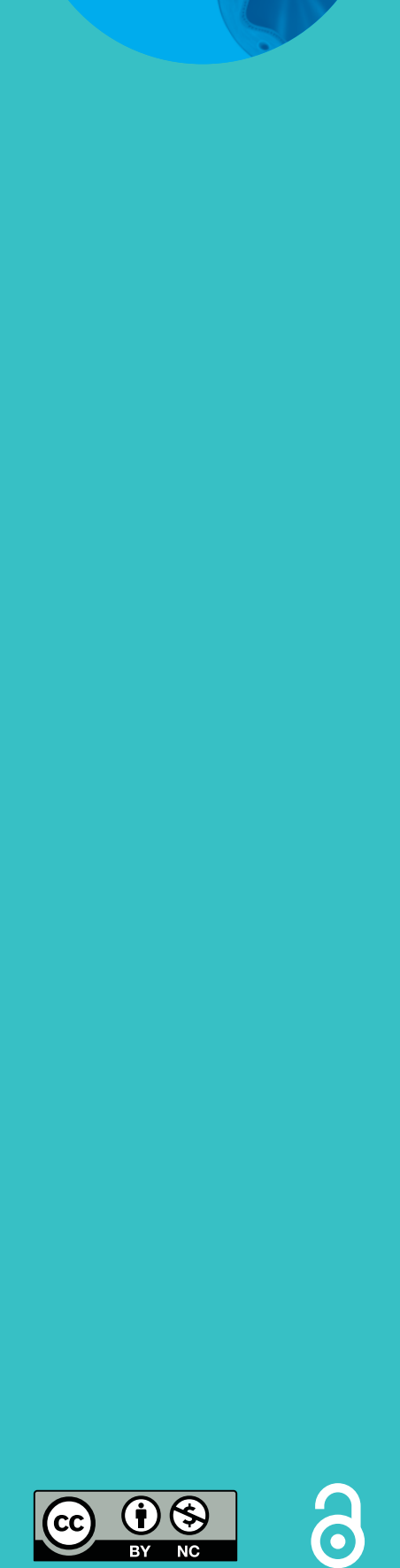

\section{Prevention of COPD exacerbations: medications and other controversies}

\author{
Jørgen Vestbo ${ }^{1}$ and Peter Lange ${ }^{2,3}$
}

Affiliations: ${ }^{1}$ Centre for Respiratory Medicine and Allergy, Institute of Inflammation and Repair, Manchester Academic Health Science Centre, University Hospital of South Manchester NHS Foundation Trust,

Manchester, UK. ${ }^{2}$ Institute of Public Health, University of Copenhagen, Copenhagen, Denmark. ${ }^{3}$ Department of Respiratory Medicine, Hvidovre University Hospital, Hvidovre, Denmark.

Correspondence: Jørgen Vestbo, Education and Research Centre, University Hospital of South Manchester NHS Foundation Trust, Wythenshawe Hospital, Southmoor Road, Manchester, M23 9LT, UK.

E-mail: jorgen.vestbodmanchester.ac.uk

ABSTRACT Exacerbations have significant impact on the morbidity and mortality of patients with chronic obstructive pulmonary disease. Most guidelines emphasise prevention of exacerbations by treatment with long-acting bronchodilators and/or anti-inflammatory drugs. Whereas most of this treatment is evidence-based, it is clear that patients differ regarding the nature of exacerbations and are likely to benefit differently from different types of treatment. In this short review, we wish to highlight this, suggest a first step in differentiating pharmacological exacerbation prevention and call for more studies in this area. Finally, we wish to highlight that there are perhaps easier ways of achieving similar success in exacerbation prevention using nonpharmacological tools.

@ERSpublications

More targeted pharmaceutical, and perhaps nonpharmaceutical, interventions are needed to prevent COPD exacerbation http://ow.ly/LQFcB

Received: April 062015 | Accepted: April 152015

Conflict of interest: Disclosures can be found alongside the online version of this article at erj.ersjournals.com

Copyright $\odot$ ERS 2015. This article is open access and distributed under the terms of the Creative Commons Attribution Non-Commercial Licence 4.0. 


\section{Introduction}

Exacerbations of chronic obstructive lung disease (COPD) are the source of significant suffering for patients, a strain on many healthcare systems and associated with significant costs [1,2]. Viral infections seem to be implicated in approximately half of all exacerbations and only a quarter of exacerbations seem unrelated to infection [3]. Prevention of COPD exacerbations is an important part of the management of COPD and the most recent strategy document from the Global Initiative for Chronic Obstructive Lung Disease emphasises assessment of risk of exacerbations as a central part of the assessment of any COPD patient $[4,5]$. In patients at high risk of exacerbations, management should be aimed at risk reduction. As future exacerbations are best predicted by history of previous exacerbations [6], these patients are often labelled as "frequent exacerbators" [7], and pharmacological treatment is particularly aimed at this patient group [5].

Little has been done in order to identify if certain patients would benefit more from one type of preventive strategy than another. Although perhaps not real personalised medicine, any attempt at a strategy to focus treatment to those most likely to benefit from it will enter into the uneasy area between evidence-based medicine and personalised medicine [8]; i.e. large-scale trials with hard outcomes for personalised treatments are not likely to be performed in the near future, if ever. We wish, nevertheless, to open a discussion on whether such a strategy is feasible based on current knowledge - without claiming that the time is ripe for evidence-based guidance. We also want to highlight that nonpharmacological strategies for preventing exacerbations could potentially have a significant effect on risk reduction.

\section{Preventive pharmacological treatments Bronchodilators}

Long-acting bronchodilators have been shown to reduce exacerbations by $10-20 \%$ [5, 9]. Most of the evidence comes from studies including patients with severe to very severe COPD with a history of at least one exacerbation in the year prior to study inclusion. Exacerbation outcomes in these studies have often been broadly defined without limitation in treatment; i.e. exacerbations treated with bronchodilators, systemic corticosteroids and/or antibiotics.

The most likely mode of action of bronchodilators is a reduction in dynamic hyperinflation known to be the mechanism behind the increased breathlessness in many patients [9]. There are few good comparisons between long-acting $\beta_{2}$-agonists and long-acting anticholinergics (LAMAs) but in the POET study, once-daily tiotropium was superior to twice-daily salmeterol in reducing time to first exacerbation [10]. Long-acting bronchodilators are unlikely to have major anti-inflammatory effects [11] and although LAMAs could potentially have a beneficial effect in reducing mucus hypersecretion associated with an increased risk of exacerbations, data supporting this mechanism are sparse. Combining two long-acting bronchodilators leads to significantly better lung function but only marginally improved reduction in exacerbation risk [12] and it seems unlikely that all COPD patients at risk of exacerbation will benefit from double treatment. We believe that long-acting bronchodilators do not affect the frequency of exacerbations per se; however, through reducing breathlessness, they can be seen to increase the threshold at which a given patient will consider their worsening sufficiently severe to be labelled an exacerbation. This is illustrated in figure $1 \mathrm{a}$ and $\mathrm{b}$.

In our view, long-acting bronchodilators are therefore likely to be efficacious in preventing any type of exacerbation independent of origin.

\section{Anti-inflammatory drugs}

The rationale behind using an anti-inflammatory drug to reduce risk of exacerbations will probably differ from that of long-acting bronchodilators. The assumed mechanism of action would come from the drug modifying the acute inflammatory response to bronchial infection or exposure to airway irritants accompanying an exacerbation and giving rise to symptoms associated with an exacerbation. For inhaled corticosteroids (ICS), this could result in reduction of eosinophilic inflammation, most often accompanying virally induced exacerbations [3]. This is schematically shown in figure 1c. As anti-inflammatory drugs will be expected to have a lesser effect on lung function, including dynamic hyperinflation, than bronchodilators, it seems reasonable to assume that they may not affect all exacerbations equally. Instead, they will only exert their effect on certain exacerbations, dependent on the inflammatory profile of the exacerbation. Two classes of anti-inflammatory drugs are currently registered for exacerbation prevention, phosphodiesterase-4 (PDE4) inhibitors and ICS.

\section{PDE4 inhibitors}

PDE4 inhibitors reduce inflammation by inhibiting the breakdown of intracellular cyclic AMP [13]. In initial studies of roflumilast, the only registered PDE4 inhibitor, there was a limited effect on exacerbations 


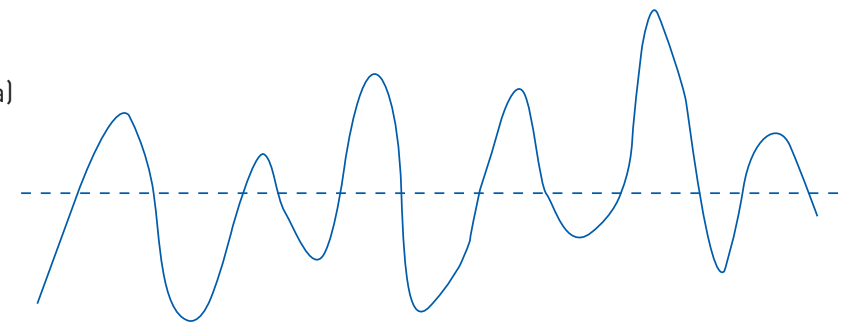

b)

FIGURE 1 The symptomatic threshold for exacerbations and how treatments are likely to reduce the rate of exacerbations. a) Variations over time (solid line) and how worsening exceeding the threshold (dotted horizontal line) are registered as exacerbations. b) Long-acting bronchodilators reduce symptoms by increasing the threshold at which patients perceive an exacerbation and how fewer exacerbations are registered as a result. c) Anti-inflammatory treatment may modulate inflammation and, thus, symptoms by reducing the amplitude of the symptomatic changes, resulting in fewer exacerbations.
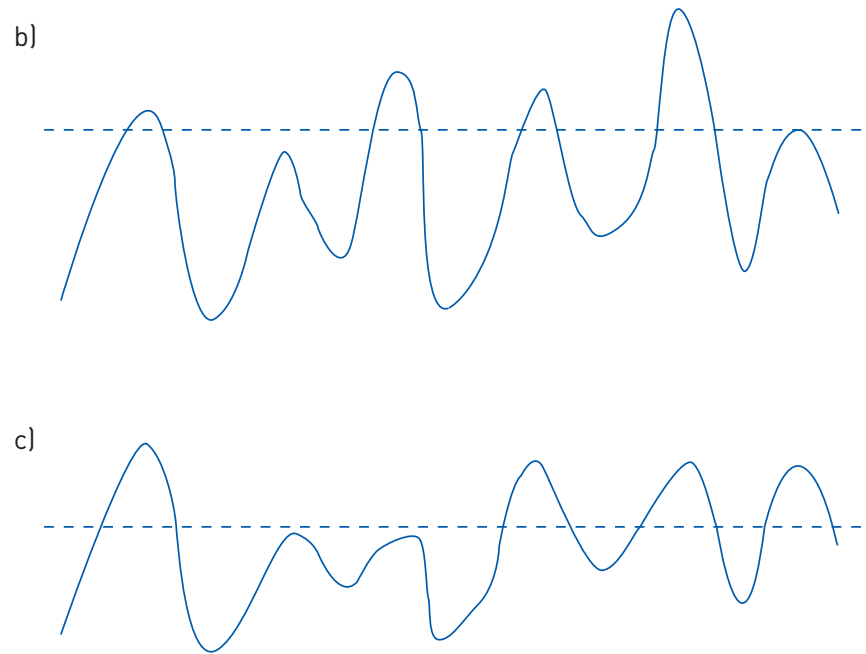

$[14,15]$. However, when inclusion criteria were narrowed to patients with forced expiratory volume in $1 \mathrm{~s}$ (FEV1) less than $50 \%$ of predicted, chronic bronchitis and a history of at least one treated exacerbation within the last year, studies found a 15-20\% reduction of exacerbations treated with systemic corticosteroids [16]. A recent study also found efficacy in patients already treated with a combination of long-acting bronchodilators and an ICS [17]. To date, no study has been carried out with exacerbations treated with antibiotics alone as an outcome. Adverse effects, in particular gastrointestinal problems, are seen more frequently in patients treated with an oral PDE4 inhibitor than in patients receiving inhaled bronchodilators or ICS [5].

Based on current evidence, roflumilast should only be used for exacerbation prevention in patients with an FEV1 less than $50 \%$ of predicted, chronic bronchitis and a history of frequent exacerbations treated with systemic corticosteroids. Caution is warranted in patients with low body mass index, due to the risk of weight loss, and in patients with frequent exacerbations characterised by purulent sputum who are treated with antibiotics, as no data on efficacy exist in this patient population.

\section{Inhaled corticosteroids}

It seems fair to state that ICS were initially used in COPD based on little else than the fact that they worked well in asthma. Subsequent trials showed that they could reduce exacerbations [18-20] but topics such as study methodology [21, 22], mechanism of action and safety [23] remain issues of debate - often heated debate with few nuances [24].

Large-scale trials have shown a reduction in exacerbations treated with systemic corticosteroids and/or antibiotics in patients treated with ICS [18-20]. Except for the TORCH trial [20], and recent trials with a combination of fluticasone furoate and vilanterol [25], virtually all studies showing an effect on exacerbations have included patients with an FEV1 less than $50 \%$ of predicted and a history of at least one treated exacerbation in the previous year. In addition, the effect is clearly most significant for exacerbations treated with corticosteroids [20] and some trials have only used corticosteroid treated exacerbations as outcome $[26,27]$. It seems obvious that the effect on exacerbations associated with bacterial infection is, at most, negligible. ICS have also been persistently been associated with an increased risk of pneumonia $[20,23,28,29]$, although data indicate that in COPD patients with pneumonia, treatment with ICS is associated with a favourable pneumonia outcome [30]. Many patients currently treated with ICS can be taken off treatment [31]. A recent post hoc analysis of two trials including the ICS fluticasone furoate has 
shown that blood eosinophils are markers of increased efficacy of treatment with ICS [32], findings that are supported by studies of biomarkers and response to oral corticosteroids during an exacerbation of COPD [33]. No prospective study has yet used blood eosinophils for treatment guidance and the above findings, so far, only relate to patients seen in secondary and tertiary care.

Based on current evidence, ICS should only be used for exacerbation prevention in patients with an FEV1 less than $50 \%$ of predicted and a history of frequent exacerbations treated with systemic corticosteroids. We have deliberately stated both criteria, as we believe that low lung function, in itself, is too weak a predictor of future exacerbations, and evidence in subjects with an FEV $1>50 \%$ is still too weak. ICS could be considered in patients with more preserved lung function if they have a history of frequent exacerbations with clear efficacy of systemic corticosteroids. Caution is warranted in patients with frequent exacerbations characterised by purulent sputum and treated with antibiotics. In these patients, as well as in patients with a history of recent pneumonia, treatment should be restricted to subjects with an eosinophil count of 300 or more per $\mu \mathrm{L}$ in peripheral blood in the stable phase.

\section{Antibiotics}

Antibiotics may reduce risk of exacerbations in patients with lower airway colonisation, and frequent exacerbations characterised by increased phlegm, purulent sputum and fever/malaise. Efficacy has been shown for fluoroquinolones and macrolides; for the latter, not just on exacerbations related to lower respiratory tract bacterial infection $[34,35]$.

However, whereas most drugs may lead to adverse events in the patient taking the drug, the prophylactic use of antibiotics is associated with a risk of harm to others through an increase in antibiotic resistance related to more widespread use of antibiotics [36]. Subgroup analyses of the largest efficacy trials of azithromycin showed that this drug was least efficacious in patients already on recommended preventive therapies, patients with more severe disease and active smokers [35, 37].

Based on current evidence, we would recommend not to use macrolides for exacerbation prevention in these subgroups of patients and to stop treatment in patients where an effect is not obvious within 6 months at the most.

\section{Comment}

We are well aware that the above suggestion for a more narrow selection of patients to be treated with anti-inflammatory drugs is controversial and, to some, provocative. We fully accept that the evidence base is weak and that far more studies are needed before evidence-based guidance can be issued. However, we doubt that more restrictive large-scale trials are likely to be carried out in large numbers in the near future, and without a push to start implementing knowledge from various other sources, we are unlikely to progress and serve our patients. We need to get away from simplistic discussions and urge clinicians, as well as the pharmaceutical industry, to accept that patients in daily clinical practice vary much more than the study populations included in usual efficacy trials on which we base our recommendations.

\section{Preventive nonpharmacological treatments}

Pulmonary rehabilitation delivered in a stable state is an established component of COPD management, and aims primarily to reduce symptoms, improve functional capacity and increase patient participation [38]. Studies indicate that it also may reduce the frequency and duration of subsequent exacerbations [39]. Rehabilitation delivered in the post-acute recovery stage may also reduce the risk of readmissions and even mortality [40], although a recent large pragmatic trial questions whether these results can be generalised [41, 42].

Vaccination is another area that could deserve attention. Influenza vaccination has been highlighted as a possible means for reducing exacerbation rates. Still, only one randomised controlled study has specifically studied influenza vaccination in COPD patients [43]. In this study, rate of hospitalisations due to influenza and pneumonia was significantly reduced (adjusted risk ratio $0.48, \mathrm{p}=0.008$ ), as was risk of death (adjusted odds ratio 0.30, $\mathrm{p}<0.001$ ); no effect on outpatient visit frequency was found. A Dutch study has considered influenza vaccination cost-effective in patients with chronic lung diseases [44] and, indeed, most countries now include patients with chronic lung diseases among those who should receive vaccination. Considerable benefits have also been shown for pneumococcal vaccination $[45,46]$ but, again, the evidence base is limited. Studies of oral vaccination against Haemophilus influenzae have shown conflicting results and, in general, the evidence for effectiveness does not suggest the widespread use of these vaccines [47].

However, simpler measures are also likely to have an effect on reducing risk of exacerbations, morbidity and mortality in COPD [48]. As up to $50 \%$ of exacerbations are related to viral infections, focus on hand hygiene seems warranted, as this can reduce transfer of infection [49]. Another factor relates to clothing. In his review, BuRge [48] shows how proper clothing is associated with better survival in winter months. It 
seems probable - but is poorly documented - that caring for sick grandchildren may increase the risk of viral infections and exacerbations in the elderly COPD patient. However, whether risk avoidance is feasible in this situation is a different matter.

\section{Conclusion}

Exacerbations are important events in COPD. There is a clear need for more targeted pharmacological exacerbation prevention - even with existing drugs - and there is a clear need for more studies in this area. In addition, there are perhaps easier ways of achieving similar success in exacerbation prevention using nonpharmacological tools.

\section{References}

$1 \quad$ Anzueto A. Impact of exacerbations on COPD. Eur Respir Rev 2010; 19: 113-118.

2 Wedzicha JA, Mackay AJ, Singh R. COPD exacerbations: impact and prevention. Breathe 2013; 9: 434-440.

3 Papi A, Bellettato CM, Braccioni F, et al. Infections and airway inflammation in chronic obstructive pulmonary disease severe exacerbations. Am J Respir Crit Care Med 2006; 173: 1114-1121.

4 Vestbo J, Hurd SS, Agusti AG, et al. Global strategy for the diagnosis, management and prevention of chronic obstructive pulmonary disease, GOLD Executive Summary. Am J Respir Crit Care Med 2013; 187: 347-365.

5 Global Initiative for Chronic Obstructive Lung Disease. Global strategy for the diagnosis, management, and prevention of chronic obstructive pulmonary disease. www.goldcopd.org/guidelines-global-strategy-for-diagnosis-management. html Date last accessed: January 30, 2015. Date last updated: 2015.

6 Hurst JR, Vestbo J, Anzueto A, et al. Susceptibility to exacerbation in chronic obstructive pulmonary disease. N Engl J Med 2010; 363: 1128-1138.

7 Soler-Cataluña JJ, Rodriguez-Roisin R. Frequent chronic obstructive pulmonary disease exacerbators: how much real, how much fictitious? COPD 2010; 7: 276-284.

8 Goldberger JJ, Buxton AE. Personalized medicine vs. guideline-based medicine. JAMA 2013; 309: 24-25.

9 Wedzicha JA, Decramer M, Seemungal TA. The role of bronchodilator treatment in the prevention of exacerbations of COPD. Eur Respir J 2012; 40: 1545-1554.

10 Vogelmeier C, Hederer B, Glaab T, et al. Tiotropium versus salmeterol for the prevention of exacerbations of COPD. N Engl J Med 2011; 364: 1093-1103.

11 Powrie DJ, Wilkinson TM, Donaldson GC, et al. Effect of tiotropium on sputum and serum inflammatory markers and exacerbations in COPD. Eur Respir J 2007; 30: 472-478.

12 Wedzicha JA, Decramer M, Ficker JH, et al. Analysis of chronic obstructive pulmonary disease exacerbations with the dual bronchodilator QVA149 compared with glycopyrronium and tiotropium (SPARK): a randomised, double-blind, parallel-group study. Lancet Respir Med 2013; 1: 199-209.

13 Rabe KF. Update on roflumilast, a phosphodiesterase 4 inhibitor for the treatment of chronic obstructive pulmonary disease. Br J Pharmacol 2011; 163: 53-67.

14 Rabe KF, Bateman ED, O'Donnell D, et al. Roflumilast - an oral anti-inflammatory treatment for chronic obstructive pulmonary disease: a randomised controlled trial. Lancet 2005; 366: 563-571.

15 Calverley PMA, Sanchez-Toril F, McIvor A, et al. Effect of 1-year treatment with Roflumilast in severe chronic obstructive pulmonary disease. Am J Respir Crit Care Med 2007; 176: 154-161.

16 Calverley PM, Rabe KF, Goehring UM, et al. Roflumilast in symptomatic chronic obstructive pulmonary disease: two randomised clinical trials. Lancet 2009; 374: 685-694.

17 Martinez FJ, Calverley PMA, Goehring U-M, et al. Effect of roflumilast on exacerbations in patients with severe chronic obstructive pulmonary disease uncontrolled by combination therapy (REACT): a multicentre randomised controlled trial. Lancet 2015; 385: 857-866.

18 Szafranski W, Cukier A, Ramirez A, et al. Efficacy and safety of budesonide/formoterol in the management of chronic obstructive pulmonary disease. Eur Respir J 2003; 21: 74-81.

19 Calverley P, Pauwels R, Vestbo J, et al. Combined salmeterol and fluticasone in the treatment of chronic obstructive pulmonary disease: a randomised controlled trial. Lancet 2003; 361: 449-456.

20 Calverley PMA, Anderson JA, Celli B, et al. Salmeterol and fluticasone propionate and survival in chronic obstructive pulmonary disease. N Engl J Med 2007; 356: 775-789.

21 Suissa S. Statistical treatment of exacerbations in therapeutic trials of chronic obstructive pulmonary disease. Am J Respir Crit Care Med 2006; 173: 842-846.

22 Keene ON, Calverley PMA, Jones PW, et al. Statistical analysis of exacerbation rates in COPD: TRISTAN and ISOLDE revisited. Eur Respir J 2008; 32: 17-24.

23 Crim C, Calverley PMA, Anderson JA, et al. Pneumonia risk in COPD patients receiving inhaled corticosteroids alone or in combination: TORCH study results. Eur Respir J 2009; 34: 89-94.

24 Ernst P, Saad N, Suissa S. Inhaled corticosteroids in COPD: the clinical evidence. Eur Respir J 2015; 45: 525-537.

25 Dransfield MT, Bourbeau J, Jones PW, et al. Once-daily inhaled fluticasone furoate and vilanterol versus vilanterol only for prevention of exacerbations of COPD: two replicate double-blind, parallel-group, randomised controlled trials. Lancet Respir Med 2013; 1: 210-223.

26 Rennard SI, Tashkin DP, McElhattan J, et al. Efficacy and tolerability of budesonide/formoterol in one hydrofluoroalkane pressurized metered-dose inhaler in patients with chronic obstructive pulmonary disease. Drugs 2009; 69: 549-565.

27 Welte T, Miravitlles M, Hernandez P, et al. Efficacy and tolerability of budesonide/formoterol added to tiotropium in patients with chronic obstructive pulmonary disease. Am J Respir Crit Care Med 2009; 180: 741-750.

28 Crim C, Dransfield MT, Bourbeau J, et al. Pneumonia risk with inhaled fluticasone furoate and vilanterol compared with vilanterol alone in patients with COPD. Ann Am Thorac Soc 2015; 12: 27-34.

29 Kew KM, Seniukovich A. Inhaled steroids and risk of pneumonia for chronic obstructive pulmonary disease. Cochrane Database Syst Rev 2014; CD010115.

30 Festic E, Scanlon PD. Incident pneumonia and mortality in patients with chronic obstructive pulmonary disease. A double effect of inhaled corticosteroids? Am J Respir Crit Care Med 2015; 191: 141-148. 
31 Magnussen H, Disse B, Rodriguez-Roisin R, et al. Withdrawal of inhaled glucocorticoids and exacerbations of COPD. N Engl J Med 2014; 371: 1285-1294.

32 Pascoe S, Locantore N, Dransfield MT, et al. Blood eosinophil count as a biomarker of ICS effectiveness in reducing exacerbation rates in COPD. Eur Respir J 2014; 44: Suppl. 58, P2817.

33 Bafadhel M, Davies L Calverley PMA, et al. Blood eosinophil guided prednisolone therapy for exacerbations of COPD: a further analysis. Eur Respir J 2014; 44: 789-791.

34 Seemungal TA, Wilkinson TM, Hurst JR, et al. Long-term erythromycin therapy is associated with decreased chronic obstructive pulmonary disease exacerbations. Am J Respir Crit Care Med 2008; 178: 1139-1147.

35 Albert RK, Connett J, Bailey WC, et al. Azithromycin for prevention of exacerbations of COPD. N Engl J Med 2011; 365: 689-698.

36 Serisier DJ. Risks of population antimicrobial resistance associated with chronic macrolide use for inflammatory airway diseases. Lancet Respir Med 2013; 1: 262-274.

37 Han MK, Tayob N, Murray S, et al. Predictors of chronic obstructive pulmonary disease exacerbation reduction in response to daily azithromycin therapy. Am J Respir Crit Care Med 2014; 189: 1503-1508.

38 McCarthy B, Casey D, Devane D, et al. Pulmonary rehabilitation for chronic obstructive pulmonary disease. Cochrane Database Syst Rev 2015; CD003793.

39 van Ranst D, Stoop WA, Meijer JW, et al. Reduction of exacerbation frequency in patients with COPD after participation in a comprehensive pulmonary rehabilitation program. Int J Chron Obstruct Pulmon Dis 2014; 9: 1059-1067.

40 Puhan MA, Gimeno-Santos E, Scharplatz M, et al. Pulmonary rehabilitation following exacerbations of chronic obstructive pulmonary disease. Cochrane Database Syst Rev 2011; CD005305.

41 Greening NJ, Williams JE, Hussain SF, et al. An early rehabilitation intervention to enhance recovery during hospital admission for an exacerbation of chronic respiratory disease: randomised controlled trial. BMJ 2014; 349: g4315.

42 Maddocks M, Kon SS, Singh SJ, et al. Rehabilitation following hospitalization in patients with COPD: can it reduce readmissions? Respirology 2015; 20: 395-404.

43 Nichol KL, Baken L, Nelson A. Relation between influenza vaccination and outpatient visits, hospitalization, and mortality in elderly persons with chronic lung disease. Ann Intern Med 1999; 130: 397-403.

44 Hak E, Van Essen GA, Buskens E, et al. Is immunising all patients with chronic lung disease in the community against influenza cost effective? Evidence from a general practice based clinical prospective cohort study in Utrecht, the Netherlands. J Epidemiol Comm Health 1998; 52: 120-125.

45 Nichol KL, Baken L, Wuorenma J, et al. The health and economic benefits associated with pneumococcal vaccination of elderly persons with chronic lung disease. Arch Intern Med 1999; 159: 2437-2442.

46 Nichol KL. The additive benefits of influenza and pneumococcal vaccinations during influenza seasons among elderly persons with chronic lung disease. Vaccine 1999; 17: Suppl. 1, S91-S93.

47 Teo E, House H, Lockhart K, et al. Haemophilus influenzae oral vaccination for preventing acute exacerbations of chronic bronchitis and chronic obstructive pulmonary disease. Cochrane Database Syst Rev 2014; CD010010.

48 Burge PS. Prevention of exacerbations: how are we doing and can we do better? Proc Am Thorac Soc 2006; 3: $257-261$

49 Jefferson T, Del Mar CB, Dooley L, et al. Physical interventions to interrupt or reduce the spread of respiratory viruses. Cochrane Database Syst Rev 2011; CD006207. 